\title{
Nanobiotechnological modules as molecular target tracker for the treatment and prevention of malaria: options and opportunity
}

\author{
Jain Anamika ${ }^{1} \cdot$ Vishwakarma Nikhar $^{1} \cdot$ Gautam Laxmikant $^{1} \cdot$ Shrivastava Priya $^{1} \cdot$ Vyas Sonal $^{2} \cdot$ S. P. Vyas ${ }^{1}$ (if
}

Published online: 7 May 2020

(C) Controlled Release Society 2020

\begin{abstract}
Malaria is one of the major infectious diseases that remains a constant challenge to human being mainly due to the emergence of drug-resistant strains of parasite and also the availability of drugs, which are non-specific for their pharmacodynamic activity and known to be associated with multiple side effects. The disease has acquired endemic proportions in tropical countries where the hygienic conditions are not satisfactory while the environmental conditions favor the proliferation of parasite and its transmission, particularly through the female anopheles. It is obvious that to square up the problems, there is a need for designing and development of more effective drugs, which can combat the drug-resistant strains of the parasite. Molecular biology of the parasite and its homing into host cellular tropics provide multiple drug targets that could judiciously be considered for engineering and designing of new generation antimalarial drugs and also drug delivery systems. Though the recent reports document that against malaria parasite the vaccine could be developed, nevertheless, due to smart mutational change overs by the parasite, it is able to bypass the immune surveillance. The developed vaccine therefore failed to assure absolute protection against the malarial infection. In the conventional mode of treatment antimalarial drugs, the dose and dosage regimen that is followed at large crops up the contraindicative manifestations, and hence compromising the effective treatment. The emerging trends and new updates in contemporary biological sciences, material sciences, and drug delivery domain have enabled us with the availability of a multitude of mode and modules which could plunge upon the nanotechnology in particular to treat this challenging infection. The nanotechnology-based option may be tuned or customized as per the requirements to mark and target i.e. the infected RBCs, for targeted drug delivery.
\end{abstract}

Keywords Malaria $\cdot$ Drug resistance $\cdot$ Vaccine $\cdot$ Nanobiotechnology $\cdot$ RBC $\cdot$ Plasmodium

\section{Introduction}

Malaria has a significant effect on mankind and remains one of the most serious and prevalent infectious diseases. Although various approaches have been adopted for the eradication of malaria, still it remains a major health concern, particularly where it acquires an endemic dimension. Thus, malaria has drawn the attention of many researchers,

S. P. Vyas

vyas_sp@rediff.com; spvyas54@gmail.com

1 Drug Delivery Research Laboratory, Department of Pharmaceutical Sciences, Dr. H. S. Gour Vishwavidyalaya, Sagar, M.P. 470003, India

2 Department of Pathology, Index Medical College, Hospital \& Research Centre, Indore, M.P., India especially in developing countries. This is due to the death of the children, pregnant women, and HIV-infected patients due to malaria [1]. According to the WHO, the worldwide total number of 219 million cases of malaria were reported in 2017 and out of the reported cases, 435,000 clinical death occurred. Although the disease is reported worldwide, yet most affected areas are tropical and subtropical regions. The causative organism of malaria is a protozoan pathogen of Plasmodium species. Malaria in humans is caused by four species of Plasmodium, e.g., P. falciparum, P. vivax, $P$. malariae, and $P$. ovale. However, 5th species of Plasmodium is also reported, which normally infects animals; it is P. knowlesi. Malaria is transmitted by Plasmodium-infected female anopheles bites. Infected female anopheles injects sporozoite into the blood during its blood meal. Sporozoites travel through the vasculature from the skin and infect liver [2]. 
The possibility of complete elimination and protection against malaria needs some effective antimalarial vaccine to be developed against the pre-erythrocytic stage of the cycle that may offer effective protection. The emergence of resistance against drugs and evasion of immune could lead to excessively high morbidity and mortality. It is not only drug resistance that is developed by the parasite but also pathogen borne toxicity; thus, they are a major concern. Other factors including patient compliance, misdiagnosis, incorrect dosing, poor drug quality, and poor living conditions taken together are responsible for the failure of malaria treatment. Therefore, this seems to be an imperative that delivery systems based on the current cutting edge technologies should be developed capable of circumventing the possibilities of drug resistance development. Because of various drawbacks of present malaria treatment as highlighted above, it is desirable that an attempt should be made to replace conventional monotherapy with combination therapy which reportedly reduces the occurrence of drug resistance. However, combination therapy too could not assure complete eradication of malaria infection [3]. Artemisinin-based combination therapies (ACT) have become a primary clinical choice which results in rapid clearance of parasite. The combination therapy, however, appears to be costly and also suffers some added side effects. It is also dependent on the socioeconomic condition, drug-drug interaction, drug-food interactions, lacking the drug quality distributed in the malarious region, and self-medication which add to the existing challenges. Nevertheless, gene sequencing of $P$. falciparum and advancement in malaria genetics present several novel molecular targets for effective drug designing and also for targeted drug delivery [4]. Currently, various pharmaceutical companies and research agencies are involved in the drug discovery and development process of antimalarial therapy, which could be accomplished with the advancements of novel drugs with better pharmacokinetic profile and costeffectiveness and also suitable for the children and pregnant women [3]. Figure 1 shows the schematic representation of drawbacks of current antimalarial drug therapy.

\section{Strategies for drug targeting}

Drugs enter within the RBCs cell through diffusion across the cell membrane, which is composed of amphipathic lipids such as phospholipids and cholesterol organized in a bilayer. The erythrocytic membrane also contains proteins, which serve as receptors and transporters. Hence, antimalarial drugs can reach their target either by carrier-mediated transportation or diffusion through lipid membrane. Carrier-mediated transportation is referred to as facilitated diffusion in case energy is not utilized or active transport if energy is consumed in the process. Carrier-mediated transportation is saturable, subjected to inhibition and stereospecific. Uncharged chemicals exhibit

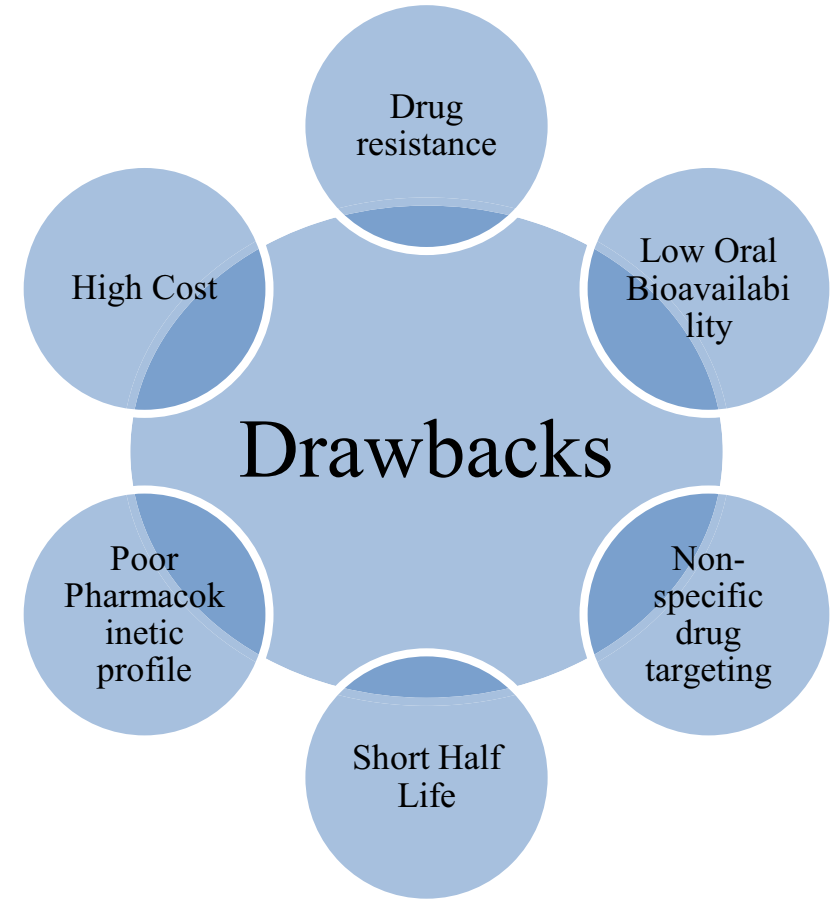

Fig. 1 Drawbacks of current antimalarial drug therapy

lipid-based diffusion; however, charged molecules are not able to cross the lipid membrane [5].

Plasmodium parasite resides within the RBCs thus escapes the host immune system. Therefore, to target the Plasmodium, the drug must cross various membranous barriers i.e. the RBCs membrane, parasitophorous vacuolar membrane, the plasma membrane of parasite, and depending on the targeting site i.e. food vacuolar membrane or apicoplast membrane. To achieve high parasite clearance rate, optimum plasma drug concentration should be attained at target, i.e., infected RBCs. Figure 2 represents the membranous systems required to be surpassed by the nanocarrier to reach the target site.

The drug targeting aims to achieve high drug concentration at the target site i.e. RBCs or liver cells to prevent the systemic side effects of the drug, caused by the non-specific biodistribution of drugs and able to enhance the drug efficacy. Nanocarriers are below $<1000 \mathrm{~nm}$ in size. They are essentially colloidal nanoparticles characterized by high surface area to volume ratio [6]. Nanocarriers should be designed appreciating some important parameters including plasma concentration which is directly proportional to the toxic effects of the drugs and efficacy that in turn directly correlates with the area under the curve (AUC). Thus, to alter the pharmacokinetic properties of the drug and achieve high drug concentration at the target site, these parameters become of paramount significance. PEGylated nanocarriers reportedly enhance the drug efficacy, reduce the dose of the drug, reduce the dosage frequency, and improve the AUC of the drug. The contact period or circulation time of nanocarrier is of importance in the treatment of malaria. Long circulation time enhances the 


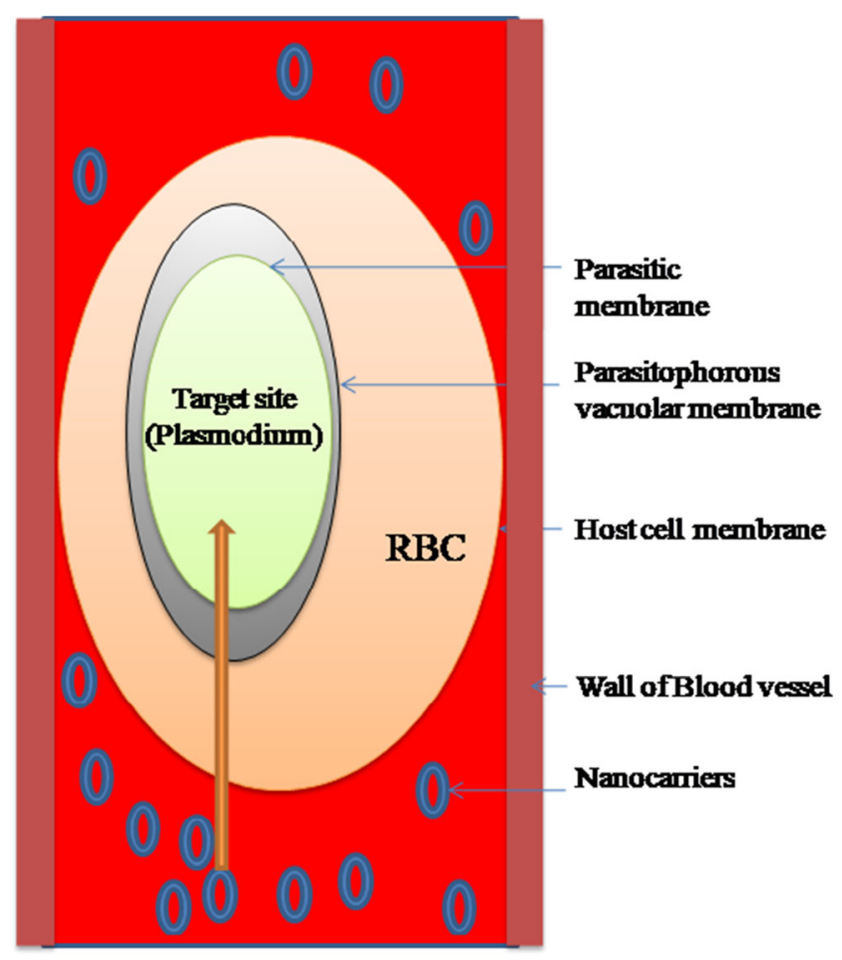

Fig. 2 Three membranous compartment system of the plasmoduim parasite via nanocarriers

interaction between RBCs and nanocarriers, ultimately leading to iRBCs specific targeting and improved efficacy [7].

The exact mechanism by which nanocarrier contained antimalarials are delivered to the infected RBCs is not clear. There are two proposed mechanisms, referred to as the traditional sequence pathway and a parallel pathway. Infected RBCs become leakier as compared with the normal RBC to fulfill their nutritional requirements from the extra RBC environment (fluid). Nanocarrier which is of the size below $<80 \mathrm{~nm}$ diameter may have direct access to the infected RBCs due to their leakiness. Thus, nanocarriers reach within the infected RBCs along with the contents. Selectivity could also be achieved by exploring this proposed mechanism because normal RBCs do not have a leaky membrane and hence a nanocarrier may enter directly into the infected RBCs only. Another proposed mechanism is membrane fusion, i.e., a drug bearing formulation fuses with iRBC membrane. There is a basic dissimilarity between these two pathways about the role of the cytosol of RBC. In the first proposed mechanism, nanocarrier is noticed to bypass the cytosol of RBC; in contrast, drug molecule passes through the cytosol in case of the second mechanism. New permeation pathways (NPP) are responsible for enhanced permeability of iRBCs to a small solute. Tubovesicular membrane (TVM) arises from the parasitophorous vacuolar membrane that extends up to RBC membrane [8] (Fig. 3). TVM is near NPP, so nanocarrier having a size below $80 \mathrm{~nm}$ may sink directly into parasite while escaping the cytosol of RBCs. The secondary mechanism involves membrane fusion and active targeting to the iRBCs. In this mechanism, the drug enters the parasite via cytosol of the iRBC [9].

There are two strategies for targeting infected RBCs viz. passive targeting and active targeting. Passive drug targeting is achieved by the use of conventional nanocarriers, i.e., polymeric nanoparticles, liposomes, or long-circulating nanocarriers (PEGylated). Active drug targeting on the other hand is achieved by the surface activation of the nanocarriers by using specific ligands to the infected RBCs associated receptors such as ligands include carbohydrate, peptide, or antibodies and proteins [10]. Figure 4 diagrammatically represents the phenomenon of active and passive targeting.

\section{(a). Parallel pathway}

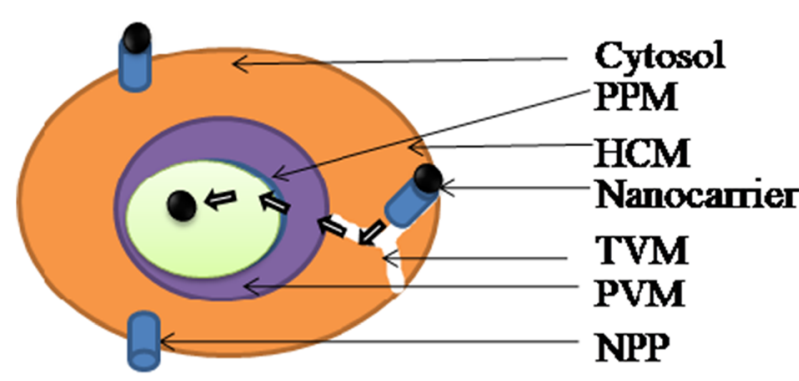

(b). Traditional sequence pathway

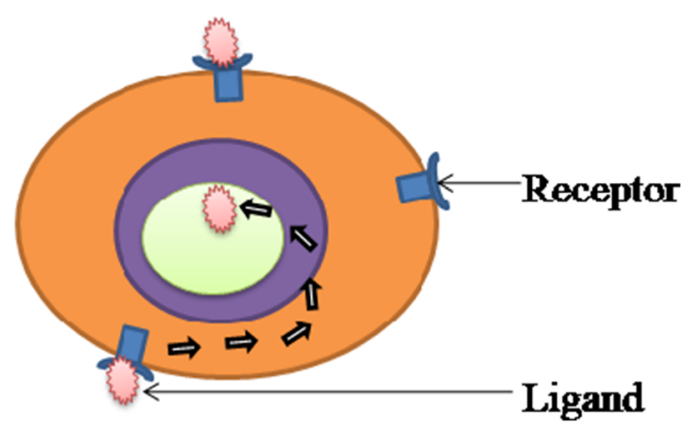

Fig. 3 Diagrammatically presentation of the proposed mechanism for drug uptake. (a) Parallel pathway in which nanocarrier having size range of below $80 \mathrm{~nm}$ reaches directly to the parasite and escaping host cell cytoplam. This is due to the "leakiness" of the infected RBC membrane. New permeation pathways (NPP) arises on the host cell membrane (HCM), which is in close pruximity eith tubulovesicular network
(TVN). TVN arises in the cytoplasm of RBC to access the nutrients from the extracellular medium. (b) Traditional sequence pathway: nanocarrier interacts with the receptor expressed on the $\mathrm{iRBC}$ membrane and then sequence crosses the host cell membrane (HCM), paracitophorous vacuolar membrane (PVM), and then parasite plasma membrane (PPM) to reach its target side 


\section{Passive Targeting}
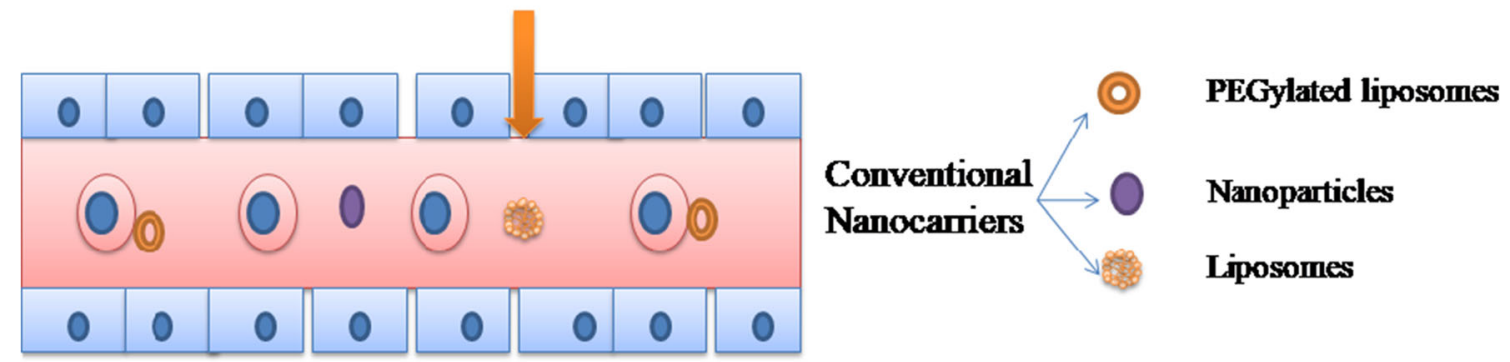

\section{Active Targeting}
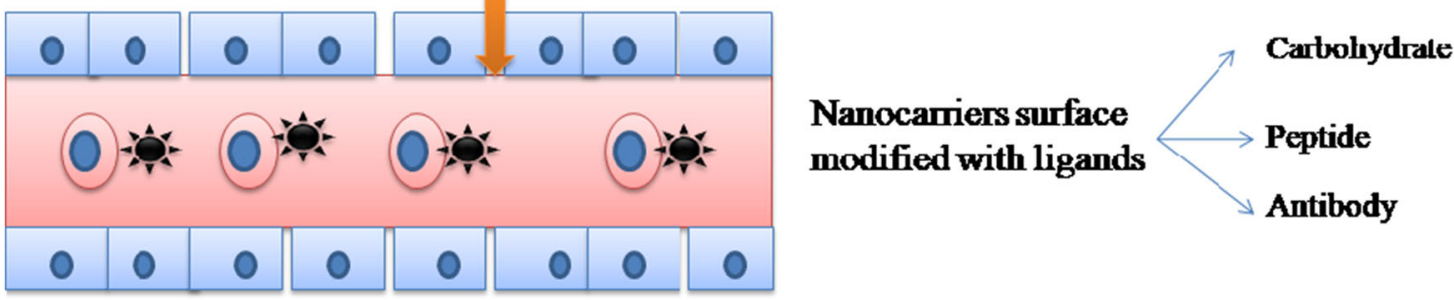

Fig. 4 Strategies for drug targeting to the infected RBC. (1) Passive drug targeting achieved by conventional nanicarriers such as liposome, polymeric nanoparticles, and long-circulating nanocarriers (PEGylated), (2)

active drug targeting which is achieved by the nanocarriers modified with the ligands suvh as carbohydrate, protein, peptide, or antibodies

\section{Passive drug targeting}

Nanocarrier-based passive targeting leads to accumulation of carrier drug in the reticuloendothelial system (RES) predominant organ. Such carriers are not specifically designed due to their defined size, charge, shape, and nature of material intercepted and captured by phagocytic cells of RES prominent organs and also circulatory phagocytic cells. The phenomenon has a unique spin-off in case of carcinoma where the leaky neovasculature exists. Due to leakiness of tumorassociated vessels, a nanocarrier retained at tumor site and thus yielding comparatively better therapeutic effects due to target accumulation of carrier and hence the drug. The permeation associated phenomenon may also operate in case of iRBCs which are leaky to meet out the requirements of nutrients specifically by needed parasite. However, no systematic studies are available in the literature on iRBCs membraneassociated that are pores, their size and their role in nutrients capture and supply. Nevertheless, the altered permeability phenomenon of iRBCs is well defined and determined that may subserve as a biomodule for passive drug targeting to such cellular destination [7].

Surface properties at large determine the internalization of the nanocarriers in the cells together with their circulation time in blood. Alteration of the surface properties of nanocarriers such as PEGylation prevents its opsonization and further clearance by the reticuloendothelial system (RES) [11]. PEGylation is the phenomenon where nanocarriers are modified with the covalent conjugation with polyethylene glycol (PEG). Moreover, circulation time also increases by an increase in the molecular weight of the PEG chain. PEGylation is used to overcome various drawbacks associated with the biopharmaceutical parameters of a drug/carrier such as pharmacokinetic properties, drug solubility, immunogenicity, and low retention time. It enhances the retention time of the nanocarrier in the blood which is a prerequisite in the case of malaria [12]. Raza et al. prepared the long circulatory liposomal formulation of maduramicin, which exhibited excellent growth inhibition of blood-stage P. falciparum parasite in culture and cures murine model of experimental malaria. They reported that maduramicin in the PEGylated liposomal formulation shows enhanced antiplasmodial activity in vitro compared with the plain maduramicin. It is active against a chloroquine-resistant murine model of malaria and devoid of toxic effects and could prevent the progression of the disease. It also displayed an extended plasma clearance rate, which enhances and favors drug accumulation particularly in infected RBCs [13]. Table 1 summarizes some of the antimalarial formulations which are based on passive drug targeting mechanism.

\section{Active drug targeting}

Nanocarriers are designed to enhance the efficacy of treatment wherein drug targeting is of particular importance. Active 
Table 1 Antimalarial formulation based on passive drug targeting mechanism

\begin{tabular}{|c|c|c|c|c|}
\hline $\begin{array}{l}\text { S. } \\
\text { no. }\end{array}$ & Drug & Formulation & Comments & Reference \\
\hline 1. & Artemisinin & $\begin{array}{l}\text { PEGylated } \\
\text { liposome }\end{array}$ & $\begin{array}{l}\text { AUC values enhanced; half-life of the } \\
\text { drug-enhanced by greater than } 5 \text { times. }\end{array}$ & {$[14]$} \\
\hline 2. & $\begin{array}{l}\text { Trans } \\
\text { platinum-- } \\
\text { chloroquine } \\
\text { diphosphate } \\
\text { dichloride (PtCQ) }\end{array}$ & $\begin{array}{l}\text { PEGylated } \\
\text { neutral and } \\
\text { cationic } \\
\text { liposomes }\end{array}$ & $\begin{array}{l}\text { Encapsulation efficiency } \\
76.1 \pm 6.7 \% \text { for neutral liposomes, } \\
70.4 \pm 9.8 \% \text { for cationic liposomes, good } \\
\text { stability }\end{array}$ & {$[15]$} \\
\hline 3. & Artesunate & PEGylated & $\begin{array}{l}\text { PEGylated artesunate enhanced water } \\
\text { solubility and circulation half-life in vivo } \\
\text { with better activity. }\end{array}$ & {$[16]$} \\
\hline 4. & $\begin{array}{l}\text { Dihydroartemisinin } \\
\text { (DHA) }\end{array}$ & $\begin{array}{l}\text { PEGylated lipid } \\
\text { nanoemulsio- } \\
\mathrm{n}\end{array}$ & $\begin{array}{l}\text { Nanoemulsion exhibits no hemolysis of the } \\
\text { RBCs and exhibited rapid parasite } \\
\text { clearance. }\end{array}$ & {$[17]$} \\
\hline 5. & Monensin & $\begin{array}{l}\text { PEGylated } \\
\text { liposome }\end{array}$ & $\begin{array}{l}\text { Formulation shows higher efficacy as } \\
\text { compared wih the free monensin in the } \\
\text { Plasmodium falciparum 3D7 culture and } \\
\text { mice model of } P \text {. berghei strains NK65 } \\
\text { and ANKA exhibited better antiparasitic } \\
\text { activity. Circulation half-life and in } \\
\text { combination with free artemisinin } \\
\text { exhibited greater parasite clearance, } \\
\text { inhibited reoccurrence }\end{array}$ & {$[18]$} \\
\hline 6. & Artesunate & Nanocapsule & $\begin{array}{l}\text { Artesunate-heparin conjugated } \\
\text { nanocapsules (ART-HEP-NCPs) } \\
\text { inhibited in vitro P. falciparum 3D7 and } \\
\text { an extended circulation in blood. }\end{array}$ & [19] \\
\hline
\end{tabular}

drug targeting can restrict the non-specific distribution of drugs to the other organs and thus decreases the side effects. Currently, carrier-based drug targeting employing nanoparticles, liposomes, NLCs, nanoemulsions, nanocapsules, and cyclodextrin has been studied and exploited for malaria treatment. Apart from these specific ligands such as carbohydrates, antibodies, peptides, or protein have been conjugated with nanocarriers, which specifically present the delivery system to the target site. Thus, active drug targeting can maximize the therapeutic effects and seemingly emerge as a promising and attractive strategy [20].

Active targeting can be achieved by the use of carbohydrate as a ligand. An intracellular pathogen can impart various modifications in the host cell to ensure their development and survival. Blood stage of the Plasmodium parasite relies on glycolysis, as the main source of ATP production. Thus, glucose is a major need of the Plasmodium parasite and to fulfill its need hexose transporters 1 (PfHT1) are expressed on the surface of the iRBCs. PfHT1 and the mammalian glucose transporter (GLUT-1) are overexpressed on the infected erythrocyte, for increased uptake of glucose [21]. Shafi et al. use carbohydrates as a ligand to specifically target the infected RBCs. Dehydroascorbic acid (DHA) exhibits competitive behavior with glucose for GLUT-1 binding. They prepared chloroquine-loaded chitosan nanoparticle with 170-200 nm in size with $50-57 \%$ entrapment efficiency. CSN is superior in terms of uptake and preferential targeting to the infected RBCs as compared with normal RBC. Parasite inhibition was achieved at $1 \mathrm{nM}$ concentration, while free drug exhibited a comparative activity at $100 \mathrm{nM}$. It is convincing that specific targeting can reduce the dose and overcome the efflux-based drug resistance [22]. Table 2 summarizes some of the antimalarial formulations which are based on active drug targeting mechanism.

\section{Nanotechnology in the treatment of malaria}

Targeted drug delivery systems can deliver the antimalarial drug selectively to the specific target, i.e., iRBCs. This is achieved by both active and passive targeting. As we discussed earlier, nanotechnology addresses various drawbacks including low oral bioavailability, short half-life, poor water solubility, the emergence of drug resistance, and nonspecific drug targeting. Nanosized carriers have drawn the attention of many researchers for their ability to minimize the side effects associated with conventional drug therapy. The goal of the nanocarriers is to protect the drug or vaccine against extracellular degradation and enhance target specific delivery thus decreasing the frequency of administration with improved efficacy and dosage regimen [30]. 
Table 2 Antimalarial formulation based on active drug targeting mechanism

\begin{tabular}{|c|c|c|c|c|c|c|c|}
\hline $\begin{array}{l}\text { S. } \\
\text { no. }\end{array}$ & Drug & Formulation & $\begin{array}{l}\text { Targeting } \\
\text { organ }\end{array}$ & Receptor & Ligand & Comments & Reference \\
\hline 1. & Primaquine (PQ) & $\begin{array}{l}\text { PEGylated } \\
\text { galactosylated } \\
\text { nanostructured lipid } \\
\text { carriers (NLCs) }\end{array}$ & Liver & $\begin{array}{l}\text { Asialoglycoprotein } \\
\text { receptor } \\
\text { (ASGP-R) }\end{array}$ & Galactose & $\begin{array}{l}\text { Sustained drug release } \\
\text { improved antiparasitic effect } \\
\text { against chloroquine-resistant } \\
\text { strain, selective accumulation } \\
\text { of NLCs with contents in } \\
\text { liver }\end{array}$ & {$[23]$} \\
\hline 2. & - & $\begin{array}{l}\text { "PS specific peptide } \\
\text { (PSP)"-conjugated } \\
\text { liposomes } \\
\text { (PSP-liposomes) }\end{array}$ & $\mathrm{RBC}$ & $\begin{array}{l}\text { Phosphatidylserine } \\
\text { (PS) }\end{array}$ & $\begin{array}{l}\text { "PS specific peptide } \\
\text { (PSP)" }\end{array}$ & $\begin{array}{l}\text { Could deliver higher amount of } \\
\text { drug to iRBCs, cause RBC } \\
\text { eryptosis }\end{array}$ & {$[24]$} \\
\hline 3. & $\begin{array}{r}\text { Chloroquine } \\
\text { phosphate }\end{array}$ & $\begin{array}{l}\text { Chitosan nanoparticles } \\
\quad(\mathrm{CSN})\end{array}$ & $\mathrm{RBC}$ & GLUT-1 & $\begin{array}{l}\text { Dehydroascorbic acid } \\
\text { (DHA) }\end{array}$ & $\begin{array}{l}\text { CSN better uptake with and } \\
\text { preferential iRBCs targeting. } \\
\text { At } 1 \mathrm{nM} \text { could inhibit } \\
\text { parasite proliferation }\end{array}$ & {$[22]$} \\
\hline 4. & $\begin{array}{l}\text { Pyronaridine and } \\
\text { atovaquone }\end{array}$ & Immunoliposome & $\mathrm{RBC}$ & Glycophorin A & $\begin{array}{l}\text { Antibodies against } \\
\text { glycophorin A }\end{array}$ & $\begin{array}{l}\text { Immunoliposomal nanovector } \\
\text { loaded with hydrophilic and } \\
\text { lipophilic drugs exhibits } \\
\text { significantly higher activity. }\end{array}$ & {$[25]$} \\
\hline 5. & $\begin{array}{l}\text { Aminoquinoline } \\
\text { and amino } \\
\text { alcohol }\end{array}$ & ImmunoPEGliposomes & $\mathrm{RBC}$ & Glycophorin A & $\begin{array}{l}\text { Mouse monoclonal } \\
\text { IgG2b antihuman } \\
\text { GPA (SM3141P) } \\
\text { and rat monoclonal } \\
\text { IgG2b antimouse } \\
\text { TER-119 } \\
\text { (AM31858PU-N) }\end{array}$ & $\begin{array}{l}\text { Significant reduction in } \\
\text { blood-stage parasitemia with } \\
\text { significantly better effect than } \\
\text { plain liposomes }\end{array}$ & {$[26]$} \\
\hline 6. & $\begin{array}{l}\text { Artemisinin } \\
\quad(\text { ART })\end{array}$ & TF-ART-NLCs & $\begin{array}{l}\text { Brain } \\
\text { (cere- } \\
\text { bral } \\
\text { malar- } \\
\text { ia) }\end{array}$ & Transferrin receptor & Transferrin (TF) & $\begin{array}{l}\text { NLCs entrapped ART could } \\
\text { express higher toxicity on the } \\
\text { U-87 MG cell line. }\end{array}$ & {$[27]$} \\
\hline 7. & Artemether & $\begin{array}{l}\text { Glyceryl-dilaurate } \\
\text { nanolipid carriers } \\
\text { (GDL-NLCs) }\end{array}$ & $\mathrm{RBC}$ & $\begin{array}{l}\text { Parasitic } \\
\quad \text { mitochondria }\end{array}$ & GDL & $\begin{array}{l}\text { GDL-NLCs lead to the } \\
\text { mitochondrial membrane } \\
\text { polarization, } \mathrm{Ca}\left(2^{+}\right) \text {ion } \\
\text { accumulation, ROS release, } \\
\text { and stage-specific lysis of the } \\
\text { infected RBCs resulted in } \\
\text { iRBCs fast clearance. It could } \\
\text { disrupt TVN and restore the } \\
\text { flexibility of the infected } \\
\text { RBCs. }\end{array}$ & {$[28]$} \\
\hline 8. & $\begin{array}{l}\text { Chloroquine } \\
\text { (CQ) }\end{array}$ & $\begin{array}{l}\text { Solid lipid nanoparticle } \\
\text { (SLN) }\end{array}$ & $\mathrm{RBC}$ & GAG-like receptors & Heparin & $\begin{array}{l}\text { Resulted in better antiparasitic } \\
\text { value against } \\
\text { chloroquine-resistant with } \\
\text { IC50 value of } 4.72 \pm 0.14\end{array}$ & {$[29]$} \\
\hline
\end{tabular}

\section{The advantages of nanocarriers as drug delivery systems}

(a) Exhibit specific targeting leading to higher intracellular accumulation of drug(s).

(b) A nanocarrier improves the pharmacokinetic profile of the drug-like oral bioavailability, plasma half-life, etc.

(c) Nanocarriers may increase the drug delivery exclusively to the target site, minimizing the side effects.

(d) Nanocarriers could avert drug resistance. (e) The frequency of administration and duration of the treatment can be reduced.

(f) Particle aggregation or blockage of the fine blood capillaries does not occur and hence can be administered by the intravenous route.

(g) Nowadays, researchers from various multi- and interdisciplinary areas such as pharmacochemistry, toxicology, and pharmacology are involved in the development of the targeted drug delivery, which is based on the extensive research experience in the various fields, thus promising outcomes are expected [30]. 
The nanotechnology can be a boon in the treatment of malaria. The present review discusses various nanocarriers commonly used for targeted drug delivery to infected RBCs.

\section{Lipid-based drug delivery carriers}

Lipid is a preferred choice as a drug vehicle due to its physiological compatibility. Lipid carriers include various ingredients like cholesterol, triglyceride, phospholipid, and fatty acid. Furthermore, lipid carriers offer various advantages over polymeric carriers such as the sustained release of the hydrophobic drugs, cost-effective, fewer chances of erosion of matrix, and most importantly the biocompatibility. The drug delivery systems that utilize various lipid carriers are liposomes, solid lipid nanoparticles (SLN) and nanostructured lipid carriers (NLCs), and self-microemulsifying drug delivery system (SMEDDS) [31].

\section{Liposome as a nanocarrier}

Liposomes are the spherical vesicles made up of phospholipids assembled in the bilayers. Liposomes can be used for the encapsulation of single or more drugs. Due to their bilayer structure, hydrophobic drugs can be incorporated in the lipid bilayers while hydrophilic drugs in or within the aqueous core [32]. Plain liposome or PEGylated liposome is extensively studied as a nanocarrier for the treatment of malaria. Liposomes are superior to nanoparticles in regard to the therapeutic index of the antimalarial drugs. They could enhance the circulation time and decrease the intrinsic toxicity and immunogenicity. PEGylation as such offers an additional advantage of enhancing the circulation time of liposomes. Thus, liposomes attracted immense attention of researchers for their potential in the treatment of malaria.

Ismail and coworkers encapsulated artesunate and its derivative into the liposomes and administered by i.v. route. They exhibited excellent in vivo results. The dimerization and self-assembly strategies were used to prepare novel amphiphilic dimeric artesunate phospholipid (Di-ART-GPC) conjugate-based liposomes. This unique approach demonstrated appreciably high drug loading and better pharmacokinetic properties. The pharmacokinetic studies reveal that liposomes and conjugate have a greater retention time in the blood. Di-ART-GPC liposomes and conjugate exhibit IC50 value of $0.39 \mathrm{nM}$ and $1.90 \mathrm{nM}$ respectively and better in vitro antiplasmodial activities without causing hemolysis. Free ART- and conventional ART-loaded liposomes show IC50 value of $5.17 \mathrm{nM}$ and $3.13 \mathrm{nM}$ respectively. The liposomes could increase the extent of parasite eradication in $P$. berghei-infected mice in vivo and delayed recrudescence and enhanced survival as compared with the free artesunate [33].

Liposomes could also deliver both the hydrophilic and hydrophobic drugs simultaneously. In combination therapy, two different drugs with different modes of action can be administered simultaneously that reduce the occurrence of drug resistance and enhance the efficacy of treatment regimen. Biosca et al. have reported a immunoliposome-based nanocarrier that incorporates both hydrophilic and hydrophobic drugs. For targeting Plasmodium-infected RBCs, the gametocytes antibodies against glycophorin A were used. Gametocyte blocking drugs such as pyronaridine and atovaquone were co-encapsulated in the glycophorin Atargeted immunoliposomes. It exhibited significantly higher activity as compared with the free drug, in vitro resulting in $50 \%$ inhibition of the growth of the parasite [25].

Antimalarial activity of monensin was reported by the Rajendran et al. They prepared liposomes using soyaphosphatidyl choline cholesterol containing either stearylamine or phosphatidic acid and different mole fractions of distearoyl phosphatidylethanolamine-methoxy-PEG 2000. In vitro and in vivo activity of the developed formulation was studied on Plasmodium falciparum cultures and murine models of Plasmodium berghei respectively. It was found to be superior to free monensin when compared. The IC50 values of $0.74 \mathrm{nM}$ and $0.39 \mathrm{nM}$ for the SA liposome and SPC:Chol-liposome with 5 mol\% DSPE-mPEG 2000 respectively were recorded, which was lower than the free monensin $(3.17 \mathrm{nM})$, and it did not show hemolysis; thus antiplasmodial activity of SA liposome and SPC:Chol-liposome with $5 \mathrm{~mol} \%$ DSPE-mPEG 2000 was greater than free monensin formulation. Long circulatory liposomes of the monensin with 5 mol\% DSPE-mPEG 2000 in combination with free artemisinin show greater parasite clearance, recrudescence inhibition, and enhanced survival [18].

Apart from the treatment, the liposomal formulation can also be used in the diagnosis of cerebral malaria (CM). CM is a severe form of malaria which is caused by the P. falciparum. Misdiagnosis or late diagnosis often delays the treatment that leads to mortality. Thus, to overcome these issues, Portnoy et al. have prepared liposomes containing an FDA approved fluorescent dye indocyanine green (ICG) for the diagnosis of CM in a murine model. Emission intensities of the liposomal formulation were high as compared with the free ICG. ICG bearing liposomes showed higher emission in the brain of the infected mice as compared with the control mice and drug-treated mice. Histopathological analysis revealed that accumulation of formulation in the vasculature of the brain is due to extensive uptake of liposomes by the activated macrophages. Thus, it can be a valuable diagnostic tool and biomarker for early detection of CM [34].

Parnham et al. reported screening of the liposomes for toxicity. Potential toxicity of the liposomes can be due to the 
metabolism of liposomal constituents. Various in vitro and in vivo tests such as thrombosis, hemolysis, cytotoxicity to L1210 mouse leukemia cells, platelet aggregation, phagocytic index, pyrogenicity, acute parenteral toxicity, and local tolerance have been carried out to rule out potential toxicity of liposomes. Hypersensitivity, however, still remains a possible toxicological risk with drugs that are administered repeatedly. However, in this context, liposomes offer various advantages over other carriers. Nevertheless, for research purposes, simple toxicity tests are sufficient; unfortunately, these simple toxicity tests are not sufficient at the advanced stages of malaria. Extensive testing of the liposomes reveals that it is safe for pharmaceutical use [35].

Liposomes are a well-established drug delivery system that could be tailored with various ranges, in terms of morphology and surface charge. They can be used for the encapsulation of hydrophilic/hydrophobic drugs. Liposomes can be formulated as a long circulatory carrier that has already exhibited better therapeutic outcomes. Thus, they hold great potential and promise to be an efficacious option adaptable for clinical application. Moreover, they should also be studied for the intrinsic toxicology in a systematic manner.

On the basis of studies as above, it can be appreciated that products based on phospholipids are a relatively safe therapeutic option and also they provide biochemically modulated targeting, wherein the lipid counterpart is an essential/ nutritional and biochemical need of parasite. To thrive upon within infected RBCs, it is a prerequisite to uptake circulatory lipids drug conjugate, which leads to infected RBCs specific drug targeting. Product as well as a carrier i.e. liposomes are seemingly devoid of toxicological implications, and represent for scientifically well-founded strategies. Nevertheless, after systematic toxicological studies, it may become the clinical reality with better clinical results of the coming future.

\section{Nanostructured lipid carrier as a nanocarrier}

As an alternative to the liposomes, emulsions, polymeric nanoparticles, and lipid nanocarriers have been explored as a drug delivery system. These are the 2 nd generation lipid carriers, developed and studied to circumvent the drawbacks associated with solid lipid nanoparticles (SLNs). NLCs are promising carriers that can incorporate hydrophobic drugs and also they are biocompatible. The NLCs have superior characteristics as compared with other lipid formulations. NLCs are composed of a mixture of lipids as liquid and solid phases that form a liquid lipid matrix, where the drug is accommodated; and hence superior characters in terms of drug stability and release characterstics are achieved [35].

Lipids play a classical role in the life cycle of Plasmodium. Lipid metabolism is not significant in the normal RBCs while its demand is increased significantly in the case of iRBCs. In order to fulfill this demand, the uptake of the lipid occurs from the host. The normal RBCs and iRBCs can be distinguished based on their lipid requirement. Based on this principle, Jain et al. prepared a glyceryl-dilaurate nano lipid carriers (GDLNLCs) for the delivery of antimalarials and tested them in a murine malaria model. Infected RBCs were selectively targeted and impaired by the GDL-NLCs. GDL was used as a targeting ligand GDL-NLCs was primarily accumulated within the mitochondria of the Plasmodium. This leads to the mitochondrial membrane polarization, $\mathrm{Ca}^{2+}$ ion accumulation, ROS release, and stage-specific lysis of the infected RBCs. GDL-NLCs also promoted the clearance of infected RBCs by the macrophages. It also disrupts the Plasmodium TVN, which is essential for the import of nutrients from the host. Optical trap studies demonstrated that GDL-NLCs restore the flexibility of the infected RBCs. The NLCs can entrap hydrophobic drugs and selectively target them to the iRBCs and hence may be a potent drug delivery carrier for the treatment of malaria [28].

Another study by Baruah et al. reports chloroquine-loaded NLCs. Chloroquine is the most widely used antimalarial for its various properties such as efficiency, stability, safety, and low cost. However, the emergence of resistance against chloroquine limits its uses. The CQ-NLCs could increase antimalarial efficacy with rapid parasitic clearance. Thus, loading of the antimalarials in the NLCs overcomes the drawbacks associated with the available conventional drugs [36].

Artemether-lumefantrine (ARM-LFN) is a WHOapproved fixed-dose combination which suffers oral bioavailability and solubility issues. The NLCs were prepared by Prabhu et al. to overcome these issues. WHO recommends the adult therapeutic dose of $80 \mathrm{mg}$ for ARM and $480 \mathrm{mg}$ for LFN (4 tablets) two times in a day. ARM-LFN NLCs were administered at the $1 / 5$ of the conventional therapeutic dose (16 mg ARM and $96 \mathrm{mg} \mathrm{LFN}$ ), which exhibited total parasite clearance and complete survival of $P$. berghei-infected mice. NLCs exhibited an increased efficacy at 1/10 daily dose of ARM-LFN. The 1/10 reduced the daily dose incorporated in two soft gelatin capsules. The capsule exhibits better stability at room temperature for a year. Thus, NLCs due to its biocompatible nature would be promising strategies for malaria therapy [37]. Table 3 summarizes some of the nanostructured lipid carrier-based antimalarial formulations.

The strategies and related literature reveal that NLCs are biocompatible and appropriate system for poorly watersoluble drugs. They have intrinsic targetability towards the cell i.e. iRBCs owing to their lipoidal nature, which satisfies the biochemical need of parasite. Thus, they may result in efficacious drug delivery system specifically suited to drugs which because of their solubility cannot be formulated in parenteral form or cleared fast by the circulation thus limited for their use. Nevertheless, such a system also needs elaborated studies relating to toxicology. 
Table 3 Nanostructured lipid carrier-based antimalarial formulations

\begin{tabular}{|c|c|c|c|c|}
\hline Drug & Formulation & ROA & Comments & Reference \\
\hline Artemether & NLC & $\begin{array}{l}\text { Intranasal } \\
\text { (i.n.) }\end{array}$ & $\begin{array}{l}\text { Significantly high concentration } \\
\text { attained in } 6 \mathrm{~h} \text { following } \\
\text { administration i.n. route due to slow } \\
\text { drug release }\end{array}$ & {$[36]$} \\
\hline Artemether & NLC & i.v. & $\begin{array}{l}\text { Exhibits greater }(P<0.005) \\
\text { antimalarial activity than injectable } \\
\text { marketed formulation, } 60 \% \text { survival } \\
\text { rate was achieved after } 31 \text { days }\end{array}$ & {$[37]$} \\
\hline Artemether-lumefantrine & NLC & Oral & $\begin{array}{l}\text { Higher antimalarial activity in terms of } \\
\text { parasitemia progression and period } \\
\text { of survival }\end{array}$ & {$[38]$} \\
\hline Artemether-lumefantrine & NLC & i.v. & $\begin{array}{l}\text { Sustained drug release and complete } \\
\text { parasitic clearance and reversal of } \\
\text { symptoms of CM, with } 100 \% \\
\text { survival in the mice infected with } \\
\text { P. berghei }\end{array}$ & [39] \\
\hline Artemether & & i.v. & $\begin{array}{l}\text { Cell line (HEK } 293 \text { T) cytotoxicity } \\
\text { studies revealed that NLCs are } \\
\text { non-toxic. Recrudescence of } \\
\text { Plasmodium is prevented after the } \\
\text { administration of the formulation. } \\
\text { Apart from these, NLCs showed } \\
\text { greater parasite clearance and better } \\
\text { survival ( } 60 \% \text { ) as compared with } \\
\text { artemether solution }(40 \%) \text {. }\end{array}$ & {$[40]$} \\
\hline
\end{tabular}

\section{Solid lipid nanoparticles as a nanocarrier}

SLNs were developed as an alternative to lipid-based nanocarriers such as liposomes, emulsions, micelles, and polymeric nanoparticles. Various biocompatible lipids used in the preparation of SLNs include precirol, cetyl alcohol, compritol, glyceryl monostearate, cetyl palmitate, stearic acid, tristearin, and trimyristin. SLNs can be synthesized without using toxic organic solvents. Thus, SLNs meet the requirement of the optimum drug delivery system for the incorporation of the lipophilic and hydrophilic drugs [41].

Heparin-functionalized nanocarriers can selectively target the iRBCs. Incorporation of the heparin enhances the stealth character and efficiently allows to bypass the reticuloendothelial system vis-to-vis an enhanced targeting of drugs with increased uptake and accumulation in the iRBCs. Heparin also synergizes the action of antimalarial drugs due to its intrinsic antimalarial activity. Chloroquine-loaded heparin-surfaced functionalized SLNs were prepared by the Muga et al. and evaluated in vitro against chloroquine-sensitive and chloroquine-resistant $P$. falciparum strains. IC50 value of CQ-SLN and CQ-Hep-SLN was found to be $4.72 \pm 0.14 \mathrm{ng} /$ $\mathrm{mL}$ and $2.41 \pm 0.27 \mathrm{ng} / \mathrm{mL}$ respectively. These findings suggest that SLNs have superior in vitro activity than chloroquine when tested on chloroquine-sensitive parasite [29].

Muller et al. reported in vitro cytotoxicity studies of the SLNs as a function of lipid matrix and surfactant. For the lipid matrix Dynasan 114 and compritol ATO 888 concentration is used and tween 80 , poloxamers, sodium dodecyl sulphate and soya lecithin is used as a surfactant. Cytotoxicity studies were carried out by measuring the viability of HL60 cells and human granulocytes. Chemiluminescence measurements were carried out to quantify the particle internalization. The results revealed that viability does not get affected by the nature of lipid. Following binding to the SLNs surface, the cytotoxic effect of surfactants such as poloxamer tends to decrease significantly. Thus, SLNs exhibited relatively low cytotoxicity as compared with other nanoparticles, i.e., polylactic/ glycolic acid and polyalkylcyanoacrylate nanoparticles. Thus, SLNs demonstrated great potential as a drug carrier system for the intravenous administration [42].

SLNs can be explored for oral as well as parental administration; they may improve the solubility of poorly aqueous soluble drug and hence their bioavailability. Furthermore, they can be fabricated for active drug targeting in case they are designed for target-oriented drug delivery. The issue related to drug payload, plasma protein interaction, targetability, nonspecific accumulation in organs, circulatory half-life, dose computation, patient compliance, and toxicological implications is required to be studied.

\section{Self-microemulsifying drug delivery system as a nanocarrier}

Self-emulsifying drug delivery system (SEDDS) is a stable mixture of active medicaments, surfactants, co-surfactant, 
and oil. Although SMEDDS are the SEDDS, which are arranged in the form of fine oil globules in water $(\mathrm{o} / \mathrm{w})$ and droplets with a diameter smaller than $50 \mathrm{~nm}$ on mild agitation in the GI tract are produced. Poorly water-soluble drugs can be effectively delivered and also the system may prevent drug degradation in the GIT. SMEDDS provides the larger surface area for the diffusion of the drug [43].

Primaquine is a gametocytocidal which is used to prevent transmission of malaria by preventing the spread of malaria. Primaquine, however, has some drawbacks like short halflife $(5.6 \mathrm{~h})$, first-pass metabolism, and dose-dependent side effects such as leukocytosis, methanoglobenmia, leukocytopenia, and hemolytic anemia in G6PD-deficient patients. Thus, frequent administration of primaquine (PQ) is needed and sometimes it shows some severe adverse effects. To overcome these issues, PQ was encapsulated in the SMEDDS to achieve higher therapeutic efficacy. Chudiwal and coworkers delivered the primaquine (PQ) as a SMEDDS to enhance liver uptake and increase efficacy against the liver stages of $P$. vivax. Pharmacodynamic efficacy was evaluated by applying Peter's Four Day Suppressive Test in a murine model. SMEDDS show higher antimalarial efficacy than marketed formulations. Results of biodistribution studies suggest that SMEDDS are specifically targeted to the liver [44]. Thus, it is a suitable carrier for liver-stage malaria.

Another study was carried out by Bhandari et al. to enhance the oral bioavailability of the artemether and lumefantrine. SMEDDS could increase aqueous solubility, which led to enhanced absorption. Optimized formulation was adsorbed on the Neusilin US2 $₫$ using a spray drying technique for conversion into solid SMEDDS. Ninety percent of the artemether and lumefantrine were released in $15 \mathrm{~min}$ in the dissolution media. Globule size of the SMEDDS was $67.74 \mathrm{~nm}$. The formulation released the contents at a faster rate in vivo as compared with the marketed tablets [45].

Curcumin and artemisinin show poor aqueous solubility, which leads to poor oral bioavailability. SMEDDS significantly improve the solubility of curcumin $(4.4 \mathrm{mg} / 3 \mathrm{~mL})$ and artemisinin $(73.4 \mathrm{mg} / 3 \mathrm{~mL})$. The optimized formulation consisted of Tween 80, PEG 400, and oleic acid. The dissolution study reveals that curcumin and artemisinin dissolved up to $63.81 \%$ and $54.91 \%$ respectively in $1.2 \mathrm{pH}$ within $1.5 \mathrm{~h}$. These studies demonstrated that SMEDDS has potential as an alternative to the conventional formulation of curcumin and artemisinin [46].

SMEDDS could be administered orally for lymphatic transportation and absorption. The materials used in their preparation are at large FDA approved. Thus, after, appropriate toxicological studies such a system(s) could be explored for their clinical application.

Table 4 summarizes some of the self-emulsifying drug delivery system(s) (SEDDS)-based antimalarial formulations.

\section{Polymer-based nanocarriers}

Polymer-based nanocarriers offer several advantages such as enhanced bioavailability, good biocompatibility, increased drug solubility, and reduced toxicity. Various polymer-based nanocarriers are polymeric nanoparticle, dendrimers, hydrogels, etc. [1].

Drug resistance is the major concern in the case of malaria; the nanotechnological attempts have been made to overcome chloroquine resistance. Dextran is a biopolymer which is approved by the US-FDA for i.v. administration. iRBCs allow access to the macromolecules as nutrients via the parasitophorous duct. Kashyap et al. prepared chloroquine dextrin nanoparticles (CHQ-DEX-NPs) by the solvent diffusion method, which are directly taken up by the iRBCs through parasitophorous duct arriving at a therapeutic concentration at the target side. IC50 value of the CHQ-DEX-NPs in sensitive 3D7 and resistant RKL9 P. falciparum strain was $0.031 \mu \mathrm{g} / \mathrm{mL}$ and $0.13 \mu \mathrm{g} / \mathrm{mL}$, which is significantly less than $0.059 \mu \mathrm{g} / \mathrm{mL}$ and $0.36 \mu \mathrm{g} / \mathrm{mL}$ of free drug [51].

Helmut Ringsdorf was first to introduce a polymer-based delivery system. Low molecular weight drug or hydrophobic bioactive agents were covalently linked with a hydrophilic polymeric carrier. Currently, polymer-drug conjugates are being used as drug delivery systems. The targeting moiety and solubilizing agents are also incorporated into the polymerdrug carriers, which further enhance the therapeutic efficacy of the bioactive. Various drawbacks associated with the current antimalarial drugs include drug toxicity, multiple drug resistance, low bioavailability, poor water solubility, and biodegradability. A polymer-drug conjugate increases bioavailability and biodegradability. The polymer-based carriers could improve the water solubility of active medicament and could effectively deliver the bioactive(s) at the target site(s). Pharmacodynamics and pharmacological and pharmacokinetic properties of drugs thus got improved when administered as polymer-drug conjugate [52].

Alven et al. have combined antibiotics with antimalarials applying polymer-drug conjugation, which provided synergistic effects. They have conjugated and incorporated antibiotics and antimalarials together onto a polyaspartamide molecule. The conjugate formation was confirmed by FTIR, 1HNMR, SEM, and XRD pattern. The conjugate exhibited amorphous nature and drug was found to be associated with the polymer(s) in chemically conjugated form. The antimalarial activity against the asexual phase of Plasmodium was recorded with 35.6-99.9 of percentage inhibition when tested in varied concentrations, i.e., 1 to $5 \mu \mathrm{M}$. The antimalarial activity of the polymer-drug conjugate has been noticeably higher as compared with free drug. The resulted synergistic action confirmed a potentiating effect of the antibiotic. Thus, these findings suggest that polymer-drug conjugate could be an attractive alternative for malaria treatment [53]. 
Table 4 Self-emulsifying drug delivery system (SEDDS)-based antimalarial formulations

\begin{tabular}{|c|c|c|c|c|}
\hline Drug & Formulation & ROA & Comments & Reference \\
\hline Artemether & $\begin{array}{l}\text { Solid dispersions } \\
\text { and } \\
\text { self-emulsified } \\
\text { solid disper- } \\
\text { sions }\end{array}$ & Oral & $\begin{array}{l}\text { The solubility of artemether is } \\
\text { enhanced. }\end{array}$ & {$[47]$} \\
\hline$\beta$-Artemether & SMEDDS & Oral & $\begin{array}{l}\text { The antimalarial activity was } \\
\text { significantly enhanced }(P<0.05) \text { as } \\
\text { compared with the marketed } \\
\text { formulation (Larither }(\text { ) }) \text {. }\end{array}$ & {$[48]$} \\
\hline $\begin{array}{l}\beta \text {-Artemether and } \\
\text { lumefantrine }\end{array}$ & SMEDDS & Oral & $\begin{array}{l}\text { SMEDDS shows superior antimalarial } \\
\text { activity with } 100 \% \text { survival as } \\
\text { compared with the innovator } \\
\left.\text { (Coartem }{ }^{\circledR}\right) \text { formulation. }\end{array}$ & [49] \\
\hline Artemether-lumefantrine & Solid SMEDDS & Oral & $\begin{array}{l}\text { Optimized SMEDDS formulation at a } \\
\text { low, medium, and high doses found } \\
\text { to be superior in terms of reduction } \\
\text { in parasitemia as well as mortality } \\
\text { in comparison with the marketed } \\
\text { tablet of equivalent dose. }\end{array}$ & {$[50]$} \\
\hline
\end{tabular}

Apart from the delivery system, polymer can also generate a potent immune effect by serving as an adjuvant. Scaria et al. have conjugated malaria antigen to a protein carrier, which provided on enhanced immunogenicity of the antigen. Malaria antigen is chemically conjugated with a carrier protein; this forms nanoparticles with greater immunogenicity. They used Pfs25 and Pfs230D1 malaria antigens separately linked to the carrier protein Exoprotein A (EPA) via thioester bond. These nanoparticles provide greater immunogenicity. Various conjugates have been reportedly prepared by using amide, glutaraldehyde, thioester, and ADH chemistry and characterized for Mw distribution, average Mw, and humoral immunogenicity evaluated in mice. The conjugate was 16$73 \mathrm{~nm}$ in size. These findings suggest that various carriers and appropriate chemistry can be used for protein-protein conjugation for effective vaccine development [54].

Polymer-based nanocarriers possess added advantages of in vivo drug release control, if they are appropriately sized and material is biodegradable could be further explored for clinical application. Nevertheless, size and surface charge are required to be evaluated for their role in nanotoxicological manifestation before they can be the acceptable drug delivery system.

Some of the polymeric-based nanocarriers are summarized in Table 5.

\section{Prodrugs as an antimalarial}

Prodrugs are chemically altered inactive drug molecules, which require chemical or enzymatic biotransformation in the body, to release their active parent drug, at the site of action where therapeutic effect is needed. Prodrugs are classified as carrier-linked prodrugs and bioprecursors. The pharmacologically active drug is attached to the carrier by a covalent bond, which is released under in vivo conditions. In contrast, bioprecursors are activated by the metabolic transformations of the functional group. Prodrug strategy is employed where a drug possesses a poor pharmacokinetic profile or where sitespecific targeted delivery is needed. Various physicochemical, pharmacokinetic, and biopharmaceutical properties like solubility, chemical stability, bioavailability, permeability, and metabolism are improved by applying prodrug approach [59].

A study carried out by Ismail et al. seems to be an interesting strategy to target iRBCs. They have reported the liposome of dimeric artesunate phospholipid, where one molecule of phospholipid could deliver simultaneously two molecules of artesunate to the iRBCs. The hypothesis is based on the demand of the lipids, which are dramatically increased during the various biological processes of Plasmodium parasite. Hence, infected RBCs can be selectively targeted via this approach. Figure 5 shows a schematic representation of targeting iRBCs via prodrug approach [33].

Some of the important prodrugs of antimalarials are summarized in Table 6.

\section{Protein/nucleic acid-based drug delivery}

Peptides exhibit high biocompatibility hence could be the material of choice for preparation of nano-drug delivery system. Curcumin is an antimalarial agent but due to its low solubility and less bioavailability, the in vivo efficacy of the curcumin is compromised. Alam and coworkers reported dehydrophenylalanine ( $\Delta \mathrm{Phe}$ ) dipeptide-based self- 
Table 5 Polymeric nanocarrierbased antimalarial formulations

\begin{tabular}{|c|c|c|c|}
\hline Drug & Formulation & Comments & Reference \\
\hline Chloroquine & $\begin{array}{l}\text { Chitosan } \\
\text { nanoparticles } \\
\text { (Ch-NP) }\end{array}$ & $\begin{array}{l}\text { Resulted in ROS-mediated } 34 \text { caspase activation, apo- } \\
\text { ptosis in the liver during Plasmodium berghei NK65 } \\
\text { infection. CS-TPP conjugation enhances the protective } \\
\text { capacity of the CQ. }\end{array}$ & [55] \\
\hline $\begin{array}{c}\text { Chloroquine and } \\
\text { azithromycin }\end{array}$ & Nanospheres & $\begin{array}{l}\text { Combination therapy exhibits synergistic action against } \\
\text { Plasmodium in vitro. The formulation could overcome } \\
\text { the problem of drug resistance. }\end{array}$ & {$[56]$} \\
\hline Bisphosphonates & $\begin{array}{l}\text { Carbon } \\
\text { nanospheres } \\
(\mathrm{CNSs})\end{array}$ & $\begin{array}{l}\text { Chloroquine conjugated bisphosphonates carbon } \\
\text { nanospheres (CNSs) exhibited excessively high anti- } \\
\text { parasitic activity parasite killing. }\end{array}$ & [57] \\
\hline Artemisinin & $\begin{array}{l}\text { Dimers and } \\
\text { dendrimers }\end{array}$ & $\begin{array}{l}\text { Antimalarial activity of the dimer and dendrimer was } \\
\text { investigated in the } P \text {. falciparum 3D7 strain and human } \\
\text { cytomegalovirus (HCMV) and found to be the most } \\
\text { active compound as compared with artesunate, } \\
\text { dihydroartemisinin, and chloroquine. Trimer is most } \\
\text { active against HCMV in vitro replication and has a } \\
\text { EC50 value of } 0.026 \mu \mathrm{m} \text {. }\end{array}$ & [58] \\
\hline
\end{tabular}

assembled nanoparticles for the delivery of curcumin. For achieving efficient delivery of curcumin, different dipeptides such as phenylalanine- $\alpha, \beta$-dehydrophenylalanine $(\mathrm{F} \Delta \mathrm{F})$, arginine- $\alpha, \beta$-dehydrophenylalanine $(\mathrm{R} \Delta \mathrm{F})$, valine- $\alpha, \beta$ dehydrophenylalanine $(\mathrm{V} \Delta \mathrm{F})$, and methonine- $\alpha, \beta$ dehydrophenylalanine $(\mathrm{M} \Delta \mathrm{F})$ which were studies for the self-assembly and curcumin loading capacity reveal that out of them $\mathrm{F} \Delta \mathrm{F}$ nanotubes exhibit the highest loading capacity nearly $68 \% \mathrm{w} / \mathrm{w}$ and an IC50 value of $3.0 \mu \mathrm{M}$. Thus, curcumin-loaded F $\Delta$ Fnanoformulation shows greater parasite inhibition as compared with free curcumin in malaria-infected mice. The biocompatible short peptide-based nanoparticles appear to be an excellent carrier for the loading of hydrophobic antimalarials [62].

$\mathrm{CM}$ is one of the most severe forms of infection of P. falciparum. Microvesicles (MV) play an important role in

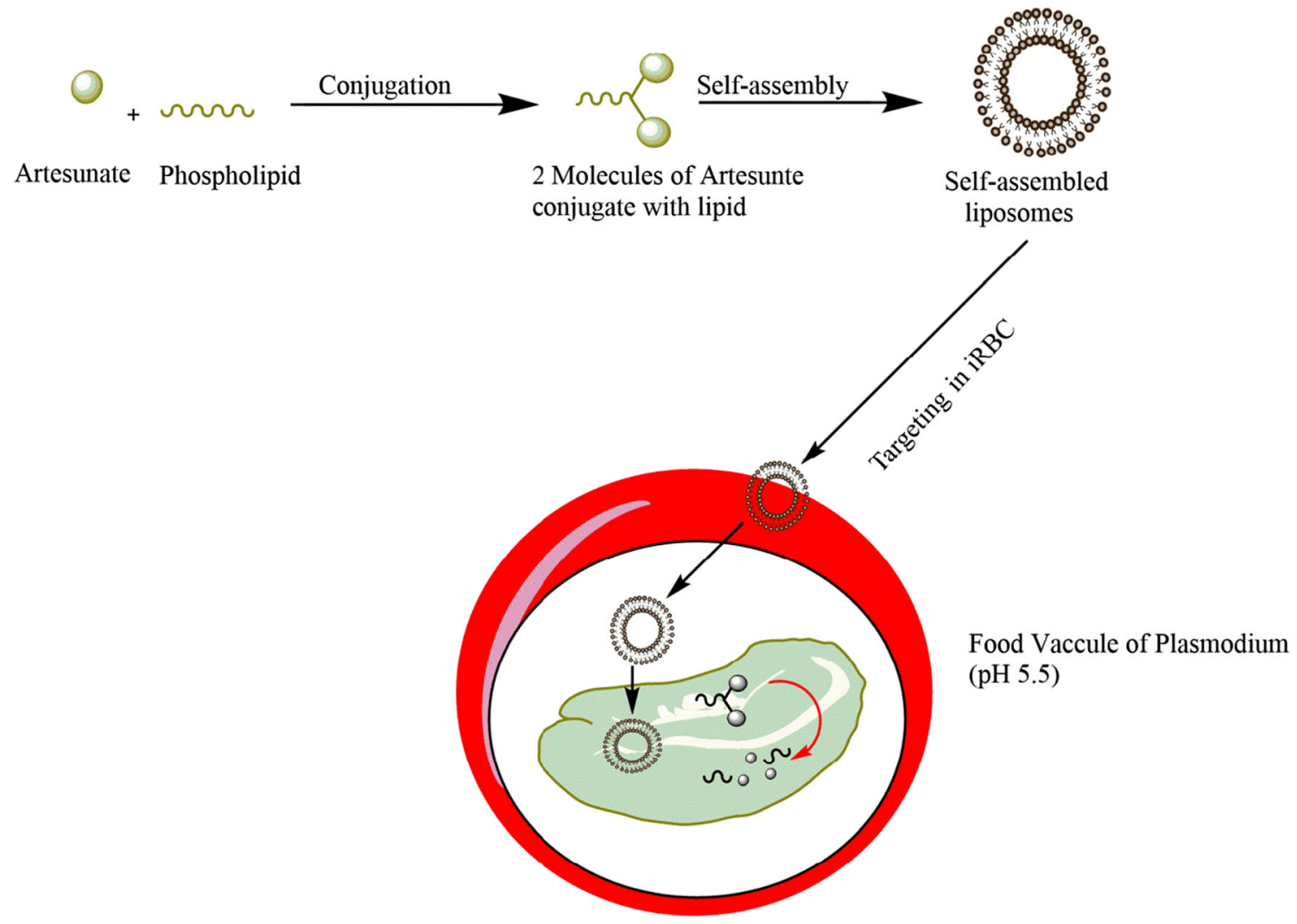

Fig. 5 Schematic representation of targeting RBC via prodrug approach 
Table 6 Prodrug-based nanocarriers for malaria

\begin{tabular}{|c|c|c|c|c|c|}
\hline Drug & Formulation & Prodrug & Target & Advantages & References \\
\hline $\begin{array}{l}\text { Endochin-like quinolones } \\
\quad \text { (ELQ-300) }\end{array}$ & - & $\begin{array}{l}\text { Alkoxycarbonate ester } \\
\text { prodrugs of ELQ-300 }\end{array}$ & $\begin{array}{l}\text { Cytochrome bc1 } \\
\text { complex }\end{array}$ & $\begin{array}{l}\text { Promising prodrug with enhanced } \\
\text { physicochemical and metabolic } \\
\text { properties and better potential for the } \\
\text { clinical formulation }\end{array}$ & {$[60]$} \\
\hline Artesunate & Liposomes & $\begin{array}{l}\text { Dimeric artesunate } \\
\text { phospholipid } \\
\text { (Di-ART-GPC) }\end{array}$ & $\begin{array}{l}\text { Parasitic } \\
\quad \text { mitochondria }\end{array}$ & $\begin{array}{l}\text { Longer retention time in blood } \\
\text { improved pharmacokinetic profile } \\
\text { and enhanced uptake by infected } \\
\text { RBCs. Enhanced parasite clearance } \\
\text { tested in } P \text {. berghei-infected mice } \\
\text { in vivo and enhanced survival as } \\
\text { compared with free drug. }\end{array}$ & {$[33]$} \\
\hline Artesunate (ART) & Nanocapsule & $\begin{array}{l}\text { Artesunate-heparin } \\
\text { conjugate (ART-HEP) }\end{array}$ & $\begin{array}{l}\text { Parasitic } \\
\quad \text { mitochondria }\end{array}$ & $\begin{array}{l}\text { Specifically, the target to iRBCs and } \\
\text { ART-HEP-NCPs exhibits higher } \\
\text { ART loading and enhanced half-life }\end{array}$ & [19] \\
\hline $\begin{array}{l}\text { 3,5-Diaryl-2-aminopyrazine } \\
\text { sulfone }\end{array}$ & - & $\begin{array}{l}\text { 3,5-Diaryl-2-aminopyrazine } \\
\text { sulfoxide }\end{array}$ & $\begin{array}{l}\text { Phosphatidylinositol } \\
\text { 4-kinase (PI4K) }\end{array}$ & $\begin{array}{l}\text { Prodrug did not improve in vivo } \\
\text { efficacy but improved drug } \\
\text { exposure with oral dosing and } \\
\text { longer half-life is achieved. }\end{array}$ & {$[60]$} \\
\hline bis-N-Alkylamidines & & $\begin{array}{l}\text { Amidoxime derivatives as a } \\
\text { prodrug }\end{array}$ & Choline & $\begin{array}{l}\text { Amidoxime prodrug significantly } \\
\text { improves oral antimalarial activity. }\end{array}$ & {$[61]$} \\
\hline
\end{tabular}

the pathogenesis of CM as a marker of severity. These are the submicron vesicles (200-1000 $\mathrm{nm}$ diameter) released from the cells in the microvasculature such as platelets, endothelial cells, erythrocyte, and leucocytes. During CM, neurological symptoms are increased as the level of MV increases. MV analysis gives a strong basis, which helps to understand the pathophysiology of CM. miRNA is the small, non-coding single-stranded RNA, which helps to control $30 \%$ of protein-coding genes via post-transcriptional regulation and RNA silencing. microRNA within the MV showed to be dysregulated in malaria. Cohen et al. worked on the microRNA cargo of MV to understand the pathogenesis of CM. miRNA changes were recorded in CBA-infected mice with $P$. berghei ANKA strain and $P$. yoelii, which are responsible for severe malaria devoid of cerebral complications hence termed as non-CM. A comparison of the MV with healthy and CM mice for miRNA expression using microarrays was made. The results reveal that miRNA plays an important role in inflammation and dysregulation during CM, which is critical for the beginning of neurological syndrome through the regulation of downstream targets [63].

Clinical development of Pfs 25 is hindered due to its limited immunogenicity. It is a transmission-blocking vaccine antigen candidate. Thus, to enhance its immunogenicity, recombinant polyhistidine-tagged Pfs 25 is mixed with the preformed liposomes which contain cobalt porphyrin-phospholipid; thus at the time of immunization, nanoliposome antigen particleization (SNAP) 762 formation takes place. The antigen is stably presented on phospholipid bilayer, without covalent modification, and hence retains antigen conformation. The histidine-tagged $P$. falciparum polypeptide was found to induce strong antibody production and could be useful in the preparation of multistage particulate vaccines using SNAP for immunization [64].

\section{Nanobiotechnology product in the market}

RTS,S (Mosquirix ${ }^{\mathrm{TM}}$ ) is the first licensed vaccine of malaria that is approved by the European Medicines Agency (EMA) for young children. RTS,S vaccine is active against $P$. falciparum, which is the most deadly parasite prevalent globally especially in the Africa region. The vaccine has been approved by the WHO for pilot production in the three African countries (Ghana, Kenya, and Malawi). RTS, S activates body immune system to fight against malaria, especially against $P$. falciparum. RTS,S is designed to arrest the Plasmodium life cycle (infection, maturation, and multiplication) in the liver [65].

In RTS,S vaccine "R" stands for central repeat region of $P$. falciparum circumsporozoite protein (CSP); "T" stands for a T cell epitope of circumsporozoite protein, and " $\mathrm{S}$ " stands for hepatitis B surface antigen (HBsAg). It forms a single fusion protein ("RTS") and it is further co-expressed within the yeast vector with free HBsAg. "RTS, S" particles are formed by the spontaneous assembly of the "RTS" fusion protein and free " $S$ " protein. The vaccine also contains adjuvants to enhance the immunogenicity; here, AS01 is used as a adjuvant and hence referred as "RTS,S/AS01" [66].

Adjuvants are added to achieve the desired adaptive immune system. It is defined as functional excipients, possesses a heterogeneous group of compounds, and can be divided into 
two broad category delivery systems or immunostimulators. Delivery systems include liposome, emulsion droplets, and immune-stimulating complexes (ISCOMs). Patternrecognition receptors (PPRs) are expressed on the antigen-presenting cells (APCs), for which co-delivery of antigen on the immunostimulator acts as a ligand. Adjuvant based on the liposomes for subunit vaccine and as immunopotentiator is multifaceted and can be customized combining (a) changing lipid composition, (b) mode of antigen and immunostimulatory association, and (c) addition of immunostimulator. Liposomes act as an adjuvant by their ability to interact with the antigen-presenting cells and increase the exposure of immunostimulator and antigen to the APCs [67].

\section{Future prospects of nanobiotechnology}

Nanobiotechnology is an emerging area of research and application being explored for its potential applications to obscure and address drug and drug delivery-related problems. Seemingly, it can improvise the existing conventional drug delivery modules and also it can improve the therapeutic outcome of the drug discernibly and may allow curtailing down the contraindicated manifestations well below the tolerable limits. Most of the nano biotechnological have demonstrated improved and effective performance at preclinical stages. However, the results at the end have been discouraging due to toxicological and interactive manifestations of such drug delivery systems. There appears to be a gap between preclinical and clinical phases inviting intensive, consistent, and sincere attention of researchers to logistically design and develop the systems for their safe and effective use. It is appreciated that the molecular interplay involved in the malaria parasite invasion and its subsequent proliferation and molecular mechanistic involved therein can open up the vistas of multiple options, opportunity, potential, and promises based on molecular events and judicious intervention thereon, which could only be possible through nanobiotechnological stratagems. The target (infected RBCs) could be selectively delivered with a load of drug which could not only eradicate the parasitemia but also the problem associated with drug resistance that emerges due to sub-therapeutic drug exposure. The nanobiotechnology may include the use of site-directing antibodies, aberrant and variant expression of protein determinant on infected cells, biodevices developed as a variant, and bioprocesses and also the smart material which could be developed by structuring a drug/drug(s) carrier selective or with proficiency to the target site. Adding to the proposed possibilities, the molecular modifications as nutrient-based prodrug and antimetabolites could be other possible diversities that can be brought in place in the designing, development, and tailoring of drug delivery systems for exclusive use in cellselective targeted drug delivery.

\section{Conclusion}

Scientific innovations, development, and international collaboration have increased the ability for effective treatment of malaria and understanding of etiology at the molecular level. Nanobiotechnology provides various opportunities, which could improve conventional malaria therapy. Poor solubility, low oral bioavailability, toxicity, chemical instability, poor pharmacokinetic properties, the short half-life of the drug, drug resistance, and non-specific drug targeting are the main drawbacks of conventional therapy. However, nanobiotechnology overcomes the abovementioned shortcomings to some extent. The journey ahead is long to recognize an effective combination of molecules, which will enhance therapeutic indices and devoid of side effects. Safety and scalability are two important parameters for targeted antimalarial therapy. Liposomes, especially PEGylated liposomes, seem to be an effective drug delivery system for incorporating antimalarial drugs. The polymeric nanocarriers are less exploited for malaria. Surface modification of the nanocarriers may improve the drug targeting and efficacy of the treatment. The nanobiotechnology thus may help design the smart, well-tolerated, low cost, and effective therapeutic drug delivery systems for the complete eradication of malaria.

Funding information This work was supported by the Indian Council of Medical Research (ICMR, New Delhi), India (Grant Number For Anamika Jain 45/38/2018-PHA/BMS, Dated 24/07/2018), for Laxmikant Gautam 45/16/2018-Nan/BMS dated 11/05/2018, and for Nikhar Vishwakarma 45/81/2018-NAN-BMS dated 30/10/2018.

\section{Compliance with ethical standards}

Conflict of interest The authors declare that there are no conflicts of interest.

\section{References}

1. Mhlwatika Z, Aderibigbe BA. Polymeric nanocarriers for the delivery of antimalarials. Molecules. 2018;23(10):2527.

2. Margaret A, Phillips JNB, Christine Manyando, van Huijsduijnen Rob Hooft, Van Voorhis Wesley C, Timothy N. C. Wells Malaria. NATURE REVIEWS | DISEASE PRIMERS 2017;3.

3. Fidock DA, Rosenthal PJ, Croft SL, Brun R, Nwaka S. Antimalarial drug discovery: efficacy models for compound screening. Nat Rev Drug Discov. 2004;3(6):509-20.

4. Baruah UK, Gowthamarajan K, Vanka R, Karri VVSR, Selvaraj K, Jojo GM. Malaria treatment using novel nano-based drug delivery systems. J Drug Target. 2017;25(7):567-81.

5. Basore K, Cheng Y, Kushwaha AK, Nguyen ST, Desai SA. How do antimalarial drugs reach their intracellular targets? Front Pharmacol. 2015;6:91. 
6. Lombardo D, Kiselev MA, Caccamo MT. Smart nanoparticles for drug delivery application: development of versatile nanocarrier platforms in biotechnology and nanomedicine. J Nanomater. 2019;2019:1-26.

7. Santos-Magalhães NS, Mosqueira VCF. Nanotechnology applied to the treatment of malaria. Adv Drug Deliv Rev. 2010;62(4-5): 560-75.

8. Kirk K. Membrane transport in the malaria-infected erythrocyte. Physiol Rev. 2001;81(2):495-537.

9. Najer A, Palivan CG, Beck H-P, Meier W. Challenges in malaria management and a glimpse at some nanotechnological approaches. In: Infectious Diseases and Nanomedicine III: Springer; 2018; 1052:103-12.

10. Pam D, Omalu I, Innalegwu D, Opemipo B, Hassan F, Kasim J, et al. An overview of application of nanotechnology in malaria control. 2017.

11. Wakaskar RR. Passive and active targeting in tumor microenvironment. Int J Drug Dev Res. 2017;9(2):37-41.

12. Veronese FM, Mero A. The impact of PEGylation on biological therapies. BioDrugs. 2008;22(5):315-29.

13. Raza M, Bharti H, Singal A, Nag A, Ghosh PC. Long circulatory liposomal maduramicin inhibits the growth of Plasmodium falciparum blood stages in culture and cures murine models of experimental malaria. Nanoscale. 2018;10(28):13773-91.

14. Isacchi $\mathrm{B}$, Arrigucci S, Marca G, Bergonzi MC, Vannucchi MG, Novelli A, et al. Conventional and long-circulating liposomes of artemisinin: preparation, characterization, and pharmacokinetic profile in mice. J Liposome Res. 2011;21(3):237-44.

15. Ibrahim S, Tagami T, Ozeki T. Effective-loading of platinumchloroquine into PEGylated neutral and cationic liposomes as a drug delivery system for resistant malaria parasites. Biol Pharm Bull. 2017;40(6):815-23.

16. Li S, Meng Q, Mao J, Li J, Xu A, Liu J, et al Pegylated artesunate derivative, pharmaceutical composition and use thereof. Google Patents; 2017.

17. Umeyor CE, Obachie O, Chukwuka R, Attama A. Development insights of surface modified lipid nanoemulsions of dihydroartemisinin for malaria chemotherapy: characterization, and in vivo antimalarial evaluation. Recent Pat Biotechnol. 2019;13(2):149-65.

18. Rajendran V, Rohra S, Raza M, Hasan GM, Dutt S, Ghosh PC. Stearylamine liposomal delivery of monensin in combination with free artemisinin eliminates blood stages of Plasmodium falciparum in culture and P. berghei infection in murine malaria. Antimicrob Agents Chemother. 2016;60(3):1304-18.

19. Ismail M, Du Y, Ling L, Li X. Artesunate-heparin conjugate based nanocapsules with improved pharmacokinetics to combat malaria. Int J Pharm. 2019;562:162-71.

20. Mizusako H, Tagami T, Hattori K, Ozeki T. Active drug targeting of a folate-based cyclodextrin-doxorubicin conjugate and the cytotoxic effect on drug-resistant mammary tumor cells in vitro. J Pharm Sci. 2015;104(9):2934-40.

21. Meireles P, Sales-Dias J, Andrade CM, Mello-Vieira J, MancioSilva L, Simas JP, et al. GLUT1-mediated glucose uptake plays a crucial role during Plasmodium hepatic infection. Cell Microbiol. 2017;19(2):e12646.

22. Shafi H, Reddy DS, Khan T, Ranjan R, Srivastava A, Vaishya S, et al. Dehydroascorbate-derivatized chitosan particles for targeting antimalarial agents to infected erythrocytes. Int J Pharm. 2017;524(1-2):205-14.

23. Baruah UK, Gowthamarajan K, Ravisankar V, Karri VVSR, Simhadri PK, Singh V, et al. Design, characterization and antimalarial efficacy of PEGylated galactosylated nano lipid carriers of primaquine phosphate. Artif Cells Nanomed Biotechnol. 2018;46(8):1809-29.
24. Tagami T, Yanai H, Terada Y, Ozeki T. Evaluation of phosphatidylserine-specific peptide-conjugated liposomes using a model system of malaria-infected erythrocytes. Biol Pharm Bull. 2015;38(10):1649-51.

25. Biosca A, Dirscherl L, Moles E, Imperial S, Fernàndez-Busquets X. An immunoPEGliposome for targeted antimalarial combination therapy at the nanoscale. Pharmaceutics. 2019;11(7):341.

26. Moles E, Galiano S, Gomes A, Quiliano M, Teixeira C, Aldana I, et al. ImmunoPEGliposomes for the targeted delivery of novel lipophilic drugs to red blood cells in a falciparum malaria murine model. Biomaterials. 2017;145:178-91.

27. Emami J, Yousefian H, Sadeghi H. Targeted nanostructured lipid carrier for brain delivery of artemisinin: design, preparation, characterization, optimization and cell toxicity. J Pharm Pharm Sci. 2018;21(1s):225s-41s.

28. Jain SA, Basu H, Prabhu PS, Soni U, Joshi MD, Mathur D, et al. Parasite impairment by targeting Plasmodium-infected RBCs using glyceryl-dilaurate nanostructured lipid carriers. Biomaterials. 2014;35(24):6636-45.

29. Muga JO, Gathirwa JW, Tukulula M, Jura WG. In vitro evaluation of chloroquine-loaded and heparin surface-functionalized solid lipid nanoparticles. Malar J. 2018;17(1):133.

30. Rathee P, Dalal A, Kumar A, Ruhil M. Nanotechnology a potential tool in malarial chemotherapy-review. Nanotechnology. 2015;24: 25.

31. Jain A, Gautam L, Vishwakarma N, Sharma R, Mody N, Dubey S, et al. Emergence of polymer-lipid hybrid systems in healthcare scenario. Multifunctional nanocarriers for contemporary healthcare applications: IGI Global; 2018: 448-70.

32. Vishwakarma N, Jain A, Sharma R, Mody N, Vyas S, Vyas SP. Lipid-based nanocarriers for lymphatic transportation. AAPS PharmSciTech. 2019;20(2):83.

33. Ismail M, Ling L, Du Y, Yao C, Li X. Liposomes of dimeric artesunate phospholipid: a combination of dimerization and selfassembly to combat malaria. Biomaterials. 2018;163:76-87.

34. Portnoy E, Vakruk N, Ameer Bishara MS, Magdassi S, Golenser J, Eyal S. Indocyanine green liposomes for diagnosis and therapeutic monitoring of cerebral malaria. Theranostics. 2016;6(2):167-76.

35. Parnham MJ, Wetzig H. Toxicity screening of liposomes. Chem Phys Lipids. 1993;64(1-3):263-74.

36. Jain K, Sood S, Gowthamarajan K. Optimization of artemetherloaded NLC for intranasal delivery using central composite design. Drug Deliv. 2015;22(7):940-54.

37. Joshi M, Pathak S, Sharma S, Patravale V. Design and in vivo pharmacodynamic evaluation of nanostructured lipid carriers for parenteral delivery of artemether: nanoject. Int J Pharm. 2008;364(1):119-26.

38. Parashar D, Aditya NP, Murthy RS. Development of artemether and lumefantrine co-loaded nanostructured lipid carriers: physicochemical characterization and in vivo antimalarial activity. Drug Deliv. 2016;23(1):123-9.

39. Prabhu P, Suryavanshi S, Pathak S, Patra A, Sharma S, Patravale V. Nanostructured lipid carriers of artemether-lumefantrine combination for intravenous therapy of cerebral malaria. Int J Pharm. 2016;513(1-2):504-17.

40. Vanka R, Kuppusamy G, Praveen Kumar S, Baruah UK, Karri VVSR, Pandey V, et al. Ameliorating the in vivo antimalarial efficacy of artemether using nanostructured lipid carriers. J Microencapsul. 2018;35(2):121-36.

41. Dolatabadi JEN, Omidi Y. Solid lipid-based nanocarriers as efficient targeted drug and gene delivery systems. TrAC Trends Anal Chem. 2016;77:100-8.

42. Müller RH, Rühl D, Runge S, Schulze-Forster K, Mehnert W. Cytotoxicity of solid lipid nanoparticles as a function of the lipid matrix and the surfactant. Pharm Res. 1997;14(4):458-62. 
43. Wu L, Qiao Y, Wang L, Guo J, Wang G, He W, et al. A selfmicroemulsifying drug delivery system (SMEDDS) for a novel medicative compound against depression: a preparation and bioavailability study in rats. AAPS PharmSciTech. 2015;16(5):10518.

44. Piyush Chudiwal SRL. Solid self-microemulsifying drug delivery system (SMEDDS) of primaquine: bio-distribution and enhanced liver uptake. J Nanomed Nanotechnol. 2018;09(01).

45. Bhandari S, Rana V, Tiwary AK. Antimalarial solid selfemulsifying system for oral use: in vitro investigation. Ther Deliv. 2017;8(4):201-13.

46. Shah A, Thakkar V, Gohel M, Baldaniya L, Gandhi T. Optimization of self micro emulsifying drug delivery system containing curcumin and artemisinin using D-optimal mixture design. 2017.

47. Tayyab Ansari M, Arshad MS, Hussain A, Ahmad Z. Improvement of solubility, dissolution and stability profile of artemether solid dispersions and self emulsified solid dispersions by solvent evaporation method. Pharm Dev Technol. 2018;23(10):1007-15.

48. Mandawgade SD, Sharma S, Pathak S, Patravale VB. Development of SMEDDS using natural lipophile: application to $\beta$-artemether delivery. Int J Pharm. 2008;362(1-2):179-83.

49. Patil S, Suryavanshi S, Pathak S, Sharma S, Patravale V. Evaluation of novel lipid based formulation of $\beta$-artemether and lumefantrine in murine malaria model. Int J Pharm. 2013;455(1-2):229-34.

50. Bhandari S, Bhandari V, Sood J, Jaswal S, Rana V, Bedi N, et al. Improved pharmacokinetic and pharmacodynamic attributes of artemether-lumefantrine-loaded solid SMEDDS for oral administration. J Pharm Pharmacol. 2017;69(11):1437-46.

51. Kashyap A, Kaur R, Baldi A, Jain UK, Chandra R, Madan J. Chloroquine diphosphate bearing dextran nanoparticles augmented drug delivery and overwhelmed drug resistance in Plasmodium falciparum parasites. Int J Biol Macromol. 2018;114:161-8.

52. Mvango S, Matshe WM, Balogun AO, Pilcher LA, Balogun MO. Nanomedicines for malaria chemotherapy: encapsulation vs. polymer therapeutics. Pharmaceutical research. 2018;35(12):237.

53. Alven S, Aderibigbe B, Balogun MO, Matshe W, Ray SS. Polymerdrug conjugates containing antimalarial drugs and antibiotics. J Drug Deliv Sci Technol. 2019;53:101171.

54. Scaria PV, Chen B, Rowe CG, Jones DS, Barnafo E, Fischer ER, et al. Protein-protein conjugate nanoparticles for malaria antigen delivery and enhanced immunogenicity. PLoS ONE. 2017;12(12): e0190312.

55. Tripathy S, Chattopadhyay S, Dash SK, Chowdhuri AR, Das S, Sahu SK, et al. Chitosan conjugated chloroquine: proficient to protect the induction of liver apoptosis during malaria. Int J Biol Macromol. 2015;74:585-600.
56. Jawahar N, Baruah UK, Singh V. Co-delivery of chloroquine phosphate and azithromycin nanoparticles to overcome drug resistance in malaria through intracellular targeting. J Pharm Sci Res. 2019;11(1):33-40.

57. Dlamini N, Mukaya H, Van Zyl R, Jansen van Vuuren N, Mbianda $\mathrm{X}$. Carbon nanospheres conjugated bisphosphonates: synthesis, characterization and in vitro antimalarial activity. Artif Cells Nanomed Biotechnol. 2018;46(sup3):S287-S96.

58. Fröhlich T, Hahn F, Belmudes L, Leidenberger M, Friedrich O, Kappes B, et al. Synthesis of artemisinin-derived dimers, trimers and dendrimers: investigation of their antimalarial and antiviral activities including putative mechanisms of action. Chem Eur J. 2018;24(32):8103-13.

59. Sanches BMFE. Is prodrug design an approach to increase water solubility? Int J Pharm. 2019;568:118498.

60. Frueh L, Li Y, Mather MW, Li Q, Pou S, Nilsen A, et al. Alkoxycarbonate ester prodrugs of preclinical drug candidate ELQ-300 for prophylaxis and treatment of malaria. ACS Infect Dis. 2017;3(10):728-35.

61. Berger O, Ortial S, Wein S, Denoyelle S, Bressolle F, Durand T, et al. Evaluation of amidoxime derivatives as prodrug candidates of potent bis-cationic antimalarials. Bioorg Med Chem Lett. 2019;29(16):2203-7.

62. Alam S, Panda JJ, Mukherjee TK, Chauhan VS. Short peptide based nanotubes capable of effective curcumin delivery for treating drug resistant malaria. J Nanobiotechnol. 2016;14(1):26.

63. Cohen A, Zinger A, Tiberti N, Grau GE, Combes V. Differential plasma microvesicle and brain profiles of microRNA in experimental cerebral malaria. Malar J. 2018;17(1):192.

64. Huang W-C, Deng B, Lin C, Carter KA, Geng J, Razi A, et al. A malaria vaccine adjuvant based on recombinant antigen binding to liposomes. Nat Nanotechnol. 2018;13(12):1174-81.

65. van den Berg M, Ogutu B, Sewankambo NK, Biller-Andorno N, Tanner M. RTS, S malaria vaccine pilot studies: addressing the human realities in large-scale clinical trials. Trials. 2019;20(1):316.

66. Gosling R, von Seidlein L. The future of the RTS, S/AS01 malaria vaccine: an alternative development plan. PLoS Med. 2016;13(4).e1001994

67. Tandrup Schmidt S, Foged C, Smith Korsholm K, Rades T, Christensen D. Liposome-based adjuvants for subunit vaccines: formulation strategies for subunit antigens and immunostimulators. Pharmaceutics. 2016;8(1):7.

Publisher's note Springer Nature remains neutral with regard to jurisdictional claims in published maps and institutional affiliations. 